ORIGINAL ARTICLE

\title{
Performance of clinical referral criteria for bone densitometry in patients under 65 years of age assessed by spine bone mineral density
}

\author{
K Kayan, D de Takats, R Ashford, J A Kanis, E V McCloskey
}

Postgrad Med J 2003;79:581-584

See end of article for authors' affiliations .....................

Correspondence to: Dr E V McCloskey, WHO Collaborating Centre for Metabolic Bone Diseases, University of Sheffield Medical School, Beech Hill Road, Sheffield' S10 2RX UK; e.v.mccloskey@shef. ac.uk

Submitted

16 December 2002

Accepted 7 May 2003
Background: A case finding strategy based on a number of established risk factors has been suggested by Royal College of Physicians' (RCP) guidelines to optimise bone densitometry referrals for assessment of osteoporosis.

Objective: The performance of clinical referral criteria was examined in women and men aged $<65$ years referred for bone mineral density (BMD) assessment.

Study design: Cross sectional observational study over six months.

Results: Though BMD tended to be lower in patients with multiple criteria for referral, differences from those referred with a single criterion were not statistically significant. The overall prevalence of osteoporosis was higher than expected in both sexes, $11.6 \%$ in women and $27.5 \%$ in men (expected prevalences were $8 \%$ and $<1 \%$ respectively). BMD was significantly lower in patients referred with a single criterion compatible with the RCP guidelines than in age matched controls or in those patients referred with non-RCP criteria (mean (SD) Z score $-0.47(1.38) \vee 0.35(1.41), p<0.001$ ). Low body mass index was also significantly associated with a lower than expected BMD. In contrast, spine BMD was higher than expected in those with self reported back pain, loss of height, or spinal curvature $(p=N S)$.

Conclusion: Most of the criteria recommended by the RCP performed well in identifying relatively younger patients with low BMD and osteoporosis. However, prior fractures and corticosteroid use did not reach statistical significance probably due to inclusion of all energy fractures, and current or past steroid use of unspecified dose or duration. Criteria like loss of height and/or spine curvature perform relatively poorly, reflecting the need for further investigation to better identify those needing BMD assessment.
L ow bone mass, as measured by bone densitometry, is widely used as a working definition of osteoporosis and — the World Health Organisation has published criteria for diagnostic categories based on the deviation of measured bone mineral density (BMD) from mean values in young healthy subjects. ${ }^{1}$ Bone densitometry when used in isolation from other clinical risk factors for fracture has a relatively low sensitivity for future fracture risk and it is widely accepted that population-wide screening is not merited, particularly at relatively young ages (for example, the perimenopausal years). ${ }^{2}{ }^{3}$ Therefore, current recommendations advocate a case finding strategy. ${ }^{45}$ Recently, the Royal College of Physicians (RCP) has published clinical guidelines for the management of osteoporosis in which recommendations for bone densitometry are suggested based on the presence of certain clinical referral criteria. ${ }^{6}$ Similar clinical referral criteria have been used locally in Sheffield for several years. ${ }^{7}$ The purpose of this study was to optimise a case finding strategy for BMD assessments by examining the relationship between the reasons for referral and the detection of lower than expected spine BMD in men and women aged less than 65 years having BMD assessments in our unit.

\section{METHOD}

The study comprised all women and men less than 65 years of age referred by general practitioners and hospital consultants for a bone densitometry scan between 1 April 1998 and 30 September 1998. One of the authors (DT) appraised all the referral letters and recorded the reasons for referral in a separate form. The referrals were grouped as in table 1. Only subjects referred for a first BMD scan were included. BMD was measured at the lumbar spine (L1-L4) of all patients using a Hologic QDR1000 or a QDR2000plus. Where necessary, vertebrae affected by fracture or osteoarthritis were removed from the computation of BMD. Daily calibration and quality assurance measures were performed as recommended by the manufacturers. The coefficient of variation of spine BMD for the Hologic equipment in our centre is approximately $1.2 \%$. We have previously determined that the manufacturer's reference data for spine BMD are appropriate for our local population in Sheffield.

The BMD measurements, $\mathrm{T}$ scores, and $\mathrm{Z}$ scores were recorded along with patient's height, weight, and body mass index. All the data were entered into a database and checked by one of the authors (KK). The subjects were classified based on their spine BMD using the World Health Organisation criteria: $\mathrm{T}$ score $<-2.5$, between -1 and -2.5 , and $>-1$ as osteoporosis, osteopenia, and normal respectively. Low body mass index per se is not specified as a criterion for referral at Sheffield (though anorexia nervosa is) but is recognised by the RCP and others as a significant risk factor. We therefore also analysed those subjects with a low body mass index defined as a value $<19 \mathrm{~kg} / \mathrm{m}^{2}$ in both sexes. The hip BMD was not undertaken as part of our routine practice in this relatively young population at the time of this study.

Abbreviations: $B M D$, bone mineral density; HRT, hormone replacement therapy; RCP, Royal College of Physicians 
Table 1 Categories and descriptions of the various reasons for referral for bone densitometry

\begin{tabular}{ll}
\hline Category & Description \\
\hline Perimenopausal & $\begin{array}{l}\text { Perimenopausal woman in whom the decision to } \\
\text { take HRT would be affected by the results of } \\
\text { BMD scan } \\
\text { Osteopenia reported or noted on radiographs } \\
\text { particularly of the spine, but also other sites }\end{array}$ \\
Osteopenia & $\begin{array}{l}\text { History of fractures (any energy) } \\
\text { Patients on long term steroids (current and past } \\
\text { users) }\end{array}$ \\
$\begin{array}{l}\text { Fractures } \\
\text { Corticosteroid users }\end{array}$ \\
Associated diseases & $\begin{array}{l}\text { History or presence of disease associated with } \\
\text { increased risk of osteoporosis } \\
\text { Oemen with early menopause (age }<45 \text { years) }\end{array}$ \\
Oyphosis & $\begin{array}{l}\text { or prolonged amenorrhoea } \\
\text { Loss of height and/or spine curvature }\end{array}$ \\
Miscellaneous & $\begin{array}{l}\text { Includes family history, patient's concern, } \\
\text { chronic fatigue, low body weight, heavy } \\
\text { smoker, bone/joint pains, recent diagnosis of } \\
\text { steroid requiring condition, heparin use, depot } \\
\text { contraceptive use, no identifiable reason } \\
\text { Women on antiresorptive therapy } \\
\text { (predominantly HRT) but no previous BMD } \\
\text { assessment }\end{array}$ \\
Treated without BMD
\end{tabular}

\section{Statistics}

The statistical analysis was performed using SPSS for Windows version 9. One way analysis of variance was used to test for statistically significant differences in age, weight, height, and body mass index among the referral groups. The individual referral groups were compared to the normal reference population of the Hologic data using a one sample $t$ test for the mean $\mathrm{Z}$ score of each of the referral criteria and the level of significance was taken as a p value $<0.05$. The expected prevalences of osteoporosis and osteopenia across the age group studied were estimated by calculating the area under the curves of spine BMD for both sexes using appropriate thresholds derived from Hologic reference data. In the event of a criterion not being associated with an increased risk of osteoporosis, a further examination was undertaken to see if subgroups at higher risk could be identified within it.

\section{RESULTS}

Of the 605 individuals aged less than 65 years referred for a first BMD measurement in the six months of the study, 554 (91.6\%) were women and 51 (8.4 \%) were men. The characteristics of the study population are shown in table 2 . The men were significantly younger $(p=0.030)$, heavier and

Table 2 Characteristics of the study population; values are means $(S D)$

\begin{tabular}{llll}
\hline & $\begin{array}{l}\text { Women } \\
(\mathbf{n}=554)\end{array}$ & $\begin{array}{l}\text { Men } \\
(\mathbf{n}=51)\end{array}$ & p Value \\
\hline Age & $50.8(8.7)$ & $47.9(12.2)$ & 0.030 \\
Height $(\mathrm{m})$ & $1.61(0.06)$ & $1.74(0.08)$ & $<0.001$ \\
Weight $(\mathrm{kg})$ & $67.6(14.8)$ & $76.6(13.8)$ & $<0.001$ \\
$\mathrm{BMl}\left(\mathrm{kg} / \mathrm{m}^{2}\right)$ & $26.1(5.3)$ & $25.5(4.5)$ & 0.415 \\
Spine BMD & $0.96(0.15)$ & $0.93(0.18)$ & 0.213 \\
$\left(\mathrm{~g} / \mathrm{cm}^{2}\right)$ & & & \\
Spine T score & $-0.81(1.40)$ & $-1.47(1.60)$ & 0.002 \\
Spine Z score & $0.05(1.37)$ & $-1.12(1.65)$ & $<0.001$ \\
Osteopenia & 35.4 & 37.3 & 0.789 \\
Osteoporosis & 11.6 & 27.5 & 0.001 \\
\hline
\end{tabular}

$B M D$, bone mineral density; $B M I$, body mass index

The T scores describe the BMD in SD units from the young adult mean $B M D$ in either sex, while the $Z$ scores relate to $S D$ units from the age and sex matched mean BMD. taller $(\mathrm{p}<0.001)$ than the women. Interestingly, the absolute mean value of the spine BMD was similar in both sexes so that the mean spine BMD in men was significantly lower than expected for their age (mean $\mathrm{Z}$ score, $\mathrm{p}<0.001$ ). Two or more clinical criteria for measurement of BMD were present in $45.7 \%$ of women and $35.3 \%$ of men. While there was evidence of a trend to have a lower spine BMD in those women with three or more criteria, the differences between mean spine BMD in individuals with single or multiple reasons for referral were not statistically significant in either sex $(\mathrm{p}=0.111$ and $\mathrm{p}=0.562$ in women and men respectively).

Of the 301 women and 33 men referred with a single criterion, $38.5 \%$ of the women were referred with a reason compatible with the RCP guidelines in contrast to $93.9 \%$ of men, reflecting the number of women referred for BMD measurement to guide decisions about use of hormone replacement therapy (HRT). The mean spine BMD was significantly lower in subjects referred with a single RCP criterion compared with those with non-RCP criteria whether expressed as absolute values of BMD $(0.92$ (0.16) $v 0.99$ $\left.(0.15) \mathrm{g} / \mathrm{cm}^{2}, \mathrm{p}<0.001\right)$ or as age and sex adjusted $\mathrm{Z}$ scores (table 3, $\mathrm{p}<0.001$ ).

\section{Reasons for referral}

The characteristics of the 301 women and 33 men referred with only one criterion for densitometry are shown in table 3. Of the women, $40.5 \%$ were characterised as perimenopausal women in whom the decision to start HRT would be influenced by the results of a BMD measurement and $8.6 \%$ were categorised as having oestrogen deficiency. The latter were significantly younger than the perimenopausal group and also had a significantly lower than expected spine BMD (mean Z score $-0.58, \mathrm{p}=0.014$ ). In contrast, women in the perimenopausal group were found to have a significantly greater than expected spine BMD (mean Z score +0.37 , $\mathrm{p}=0.001$ ) with prevalences of osteopenia and osteoporosis that were similar to or lesser than that expected from a random population sample of the same age.

The majority of the 33 men were referred either because of corticosteroid use (comprising $42.4 \%$ of single criterion referrals) or a concurrent disease associated with an increased risk of osteoporosis (comprising 30.3\% of referrals). In contrast, corticosteroid use or associated diseases only accounted for $19.0 \%$ and $7.2 \%$ respectively of all referrals in women unrelated to the menopause or oestrogen deficiency. The lower estimates in women reflected a greater number of women being referred for other reasons including prior or ongoing treatment (largely with HRT) and miscellaneous reasons that included a positive family history of osteoporosis and patient's concern ( 59 women compared with one man in total, corresponding to $38.6 \%$ and $3.0 \%$ of all referrals unrelated to menopause or oestrogen in both sexes). Back pain and height loss, or spinal curvature, were uncommon reasons for referral and similar numbers were observed in men and women. The proportions of referrals because of radiographic osteopenia $(9.1 \% \vee 5.6 \%)$ or prior fractures $(5.9 \%$ v $4.9 \%)$ were similar in both sexes.

Radiographic osteopenia referrals had the lowest BMD compared with the average expected for their ages (mean $\mathrm{Z}$ score $-0.97, p=0.003$ ) with a prevalence of osteoporosis of $45 \%$. Only $15 \%$ of such referrals had bone density values lying within the normal category. Like women with oestrogen deficiency, the patients with diseases associated with osteoporosis were significantly younger than the other patient groups. The reduction in mean spine BMD was also similar to that observed in oestrogen deficient women and was of borderline statistical significance (mean $\mathrm{Z}$ score $-0.58, p=0.065)$. Prior fractures and corticosteroid use were also associated with lower than expected average spine BMD 
Table 3 Characteristics of subjects referred with a single criterion for bone densitometry; values are mean (SD) unless stated otherwise

\begin{tabular}{|c|c|c|c|c|c|c|c|}
\hline Referral criteria & Female(n) & Male(n) & Age (years) & BMI $\left(\mathrm{kg} / \mathrm{m}^{2}\right)$ & Spine Z score & Osteoporosis (\%) & Osteopenia (\%) \\
\hline RCP criteria & 116 & 31 & $49.1(11.6)$ & $26.1(5.4)$ & $-0.47(1.38)^{\star * *}$ & 19.7 & 38.8 \\
\hline Osteopenia & 17 & 3 & $54.5(7.1)$ & $24.3(5.0)$ & $-0.97(1.29)^{* *}$ & 45 & 40 \\
\hline Oestrogen deficiency & 26 & - & $45.2(11.2)^{\dagger}$ & $25.7(5.3)$ & $-0.58(1.13)^{*}$ & 15.4 & 42.3 \\
\hline Associated diseases & 11 & 10 & $38.8(13.4)^{\dagger}$ & $26.5(7.0)$ & $-0.58(1.35)^{\#}$ & 9.5 & 38.1 \\
\hline Fractures & 27 & 3 & $54.0(9.4)$ & $26.2(4.7)$ & $-0.38(1.44)$ & 23.3 & 33.3 \\
\hline Corticosteroid users & 29 & 14 & $49.8(10.5)$ & $26.7(5.8)$ & $-0.28(1.40)$ & 14 & 41.9 \\
\hline Kyphosis & 6 & 1 & $52.9(10.4)$ & $27.2(2.4)$ & $0.21(2.12)$ & 14.3 & 28.6 \\
\hline Non-RCP criteria & 185 & 2 & $51.4(7.3)$ & $26.2(5.2)$ & $0.35(1.41)^{\star * \star}$ & 6.4 & 34.2 \\
\hline Perimenopausal & 122 & - & $52.4(4.7$ & $26.0(4.4)$ & $0.37(1.24)^{* * *}$ & 4.9 & 34.4 \\
\hline Miscellaneous & 40 & 1 & $46.0(10.9)$ & $27.0(7.5)$ & $-0.13(1.39)$ & 12.2 & 34.1 \\
\hline Back pain & 4 & 1 & $53.2(5.9)$ & $28.8(5.4)$ & $0.92(1.76)$ & 0 & 20.0 \\
\hline Treated without BMD & 19 & 0 & $56.0(5.8)^{\ddagger}$ & $24.9(3.6)$ & $1.08(1.99)^{*}$ & 5.3 & 36.8 \\
\hline
\end{tabular}

$B M D$, bone mineral density; BMI, body mass index; RCP, Royal College of Physicians.

$\dagger p \leqslant 0.001, \neq p=0.008$ compared with mean age of rest of women referred for scans; ${ }^{* * *} p \leqslant 0.001,{ }^{* *} p<0.01,{ }^{*} p<0.05$, and ${ }^{\#} p=0.065$ represent the significances of differences of the mean spine $Z$ score from 0 ( $T$ test).

(mean Z score -0.38 and -0.28 respectively) but these reductions were not statistically significant $(p=0.162$ and $\mathrm{p}=0.191$, respectively).

In contrast, women who were taking or had taken antiresorptive therapies (primarily HRT) in the absence of any previous bone density scan had the highest mean age at the time of scan, and yet had a higher than expected mean spine BMD ( $Z$ score $+1.08, p=0.029)$. Those patients referred with back pain alone (four women and one man) were heavier (not significant) and had a higher mean body mass index (not significant) than those in other categories. Spine BMD was much higher than expected for age but this was not significant $(p=0.305)$ because of the small numbers involved (4/5 had BMD lying in the normal category). Likewise, loss of height or spinal curvature was associated with a slightly higher than expected spine BMD, though one of the seven patients had a spine BMD lying in the osteoporotic category.

Regardless of the reason for referral, 28 subjects $(4.6 \%, 23$ women and five men) had a low body mass index. This group of patients were significantly younger than those with higher body mass index (mean age $44.2 v 50.9, \mathrm{p}<0.001$ ) and the mean spine $\mathrm{Z}$ score was significantly lower than expected for age $(-0.90(1.46), p=0.003)$. This effect persisted when the analysis was restricted to those individuals outside the referral categories with known effects on BMD (that is, excluding those with oestrogen deficiency, associated diseases, corticosteroid use and prior fracture, mean Z score $-0.78(1.30), p=0.021)$. Only two of the women contemplating the use of HRT had a low body mass index but both were osteoporotic. The prevalence of osteoporosis in these women with a normal body mass index $\left(20-25 \mathrm{~kg} / \mathrm{m}^{2}\right)$ was only $5.7 \%$ and this fell further in women with a higher body mass index $\left(25-30 \mathrm{~kg} / \mathrm{m}^{2}\right.$, prevalence of osteoporosis $\left.2.2 \%\right)$. No cases of osteoporosis were detected in obese women (body mass index $>30$ ) referred for a perimenopausal reason.

\section{DISCUSSION}

Our study establishes the usefulness of criteria identified within recent RCP guidelines as indications for BMD assessment. Thus, radiological evidence of osteopenia, oestrogen deficiency, and diseases associated with osteoporosis have performed well as indicators of increased osteoporotic risk in this study. While the effects of prior fracture and corticosteroid use were not statistically significant, it is important to remember that the criteria applied were relatively broad and included both high and low energy fractures or past and current use of corticosteroids of unspecified dose. Only patients referred with kyphosis failed to show a reduction in BMD but this probably reflected the absence of a prior spine radiograph to document the cause of the kyphosis. If due to degenerative changes rather than osteoporotic vertebral fracture, the kyphosis would not be expected to be associated with low bone mass. Furthermore, any degenerative changes (for example, osteophytes, end plate sclerosis, facet joint arthritis) may cause an artefactual increase in BMD. ${ }^{8}$ BMD assessments at other skeletal sites such as the forearm or hip would be more informative in such patients. BMD assessments at the forearm using dual $x$-ray absorptiometry (Osteometer DTX200) in the seven patients referred with kyphosis revealed a mean Z score of +0.02 , confirming a low risk of osteoporosis in this group of patients. If we had also measured BMD at the hip it is highly likely that the prevalence of osteopenia or osteoporosis would have been even higher in these risk groups. Total hip BMD measurements are now routinely undertaken in all clinical referrals to our unit.

In contrast to the RCP criteria, other reasons for referral did not successfully identify patients at higher risk of low bone mass. For example, mean values for spine BMD in perimenopausal women considering HRT use, current HRT users and those concerned about the risk of osteoporosis (included in miscellaneous reasons) were similar to or greater than those expected for their age. These observations may result from the self selection for referral of women who are more aware of health related issues who generally lead a healthier lifestyle and consequently have a lower prevalence of osteoporosis. The observations are compatible with the report of a lower prevalence of risk factors for osteoporosis in women self selecting to take $\mathrm{HRT}^{10}$ and a relatively low prevalence of osteoporosis in women referred from a community menopause clinic with no identifiable risk factor for osteoporosis. ${ }^{11}$ In our study, menopausal women considering the use of HRT as the sole criterion for BMD measurement comprised $40 \%$ of the total number of women referred. A similar proportion was reported in an audit of BMD scanning from a community menopause clinic. ${ }^{11}$ Thus, avoidance of the use of BMD assessments in such women would have a large impact on the throughput of a BMD unit in the setting of scanty BMD services in the UK. ${ }^{12}$ The major reason for undertaking scans in such patients is, however, to decide whether to start or continue with HRT and it would be important to determine the impact of such measurements on patient management before concluding that they should be discouraged. It has been recommended that doctors should provide adequate knowledge to these women about the other factors that are likely to influence their risk of fracture and some indicators of how the measurements might affect their lifestyle, management of their condition, and cost of medical care. ${ }^{13}$

Better use of BMD in this group may be achieved by targeting those with lower values of body mass index in 
whom the prevalence of osteoporosis was relatively high in our study ( $25 \%)$. Low body weight $(<55 \mathrm{~kg}$ ) has been shown to be associated with low bone mass in a similar clinical study. ${ }^{14}$ Better targeting of scans may be achieved in other groups of patients. For example, in seeking a family history of osteoporosis, many patients appear to confuse osteoporosis and osteoarthritis so that questions specifically about a history of low trauma fractures may enhance the detection rate for osteoporosis.

We conclude that most of the criteria recommended by the RCP as indicators for bone densitometry assessment have performed well in this study. The fact that prior fractures and corticosteroid use did not reach statistical significance probably reflected inclusion of all energy fractures, and current or past steroid use of unspecified dose or duration. This study also reiterates the important role of spine radiographs as a first investigation in patients with height loss or kyphosis and those with back pain before considering the need for a BMD measurement. Low body weight or body mass index provides a useful clinical tool for better targeting of investigation by dual $x$-ray absorptiometry.

\section{ACKNOWLEDGEMENTS}

We would like to thank Ms D Charlesworth and Ms J Bostock for performing all the BMD scans.

\section{Authors' affiliations}

K Kayan, D de Takats, R Ashford, J A Kanis, E V McCloskey, WHO

Collaborating Centre for Metabolic Bone Diseases, University of

Sheffield, Sheffield

\section{REFERENCES}

1 Consensus Development Conference. Diagnosis, prophylaxis and treatment of osteoporosis. Am J Med 1993;94:646-50.

2 World Health Organisation. Assessment of fracture risk and its application to screening for postmenopausal osteoporosis $\mathrm{WHO}$ technical support series 843. Geneva: WHO, 1994.

3 Marshall D, Johnell O, Wedel H. Meta-analysis of how well measures of bone mineral density predict occurrence of osteoporotic fractures. BMJ 1996:312:1254-9.

4 Melton LJ, Eddy DM, Johnston CC. Screening for osteoporosis. Ann Intern Med 1990;112:516-28.

5 Walker Bone K, Reid DM, Cooper C. Is screening for osteoporosis worthwhile? Br Med Bull 1998;54:915-27.

6 Royal College of Physicians (UK). Osteoporosis: clinical guidelines for prevention and management. London: RCP, 1999.

7 Anonymous. The Sheffield protocol for management of the menopause and prevention and treatment of osteoporosis. Osteoporosis 2000. 7th Revised edition. Sheffield, 2001.

8 Masud T, Langley S, Wiltshire $\mathrm{P}$, et al. Effect of spinal osteophytosis on bone mineral density measurements in vertebral osteoporosis. BMJ 1993;307:172-3.

9 Jones G, White C, Nguyen T, et al. Prevalent vertebral deformities: relationship to bone mineral density and spinal osteophytosis in elderly men and women. Osteoporos Int 1996;6:233-9.

10 Rödström K, Bengtsson C, Lissner L, et al. Pre-existing risk factor profiles in users and non-users of hormone replacement therapy: prospective cohort study in Gothenburg, Sweden. BMJ 1999;319:890-3.

11 Miles A, Weaver KE, Glasier A. A review of bone mineral density scans referred by a community-based menopause clinic in 1997. Br J Fam Plan 2000;26:136-8.

12 Compston JE, Cooper C, Kanis JA. Bone densitometry in clinical practice. BMJ 1995;310:1507-10.

13 Raisz LG. Screening for osteoporosis: a clinical, social, and economic dilemma. Mayo Clin Proc 2000;75:885-7.

14 Ballard PA, Purdie DW, Langton CM, et al. Prevalence of osteoporosis and related risk factors in UK women in the seventh decade: osteoporosis case finding by clinical referral criteria or predictive model? Osteoporos Int 1998;8:535-9.

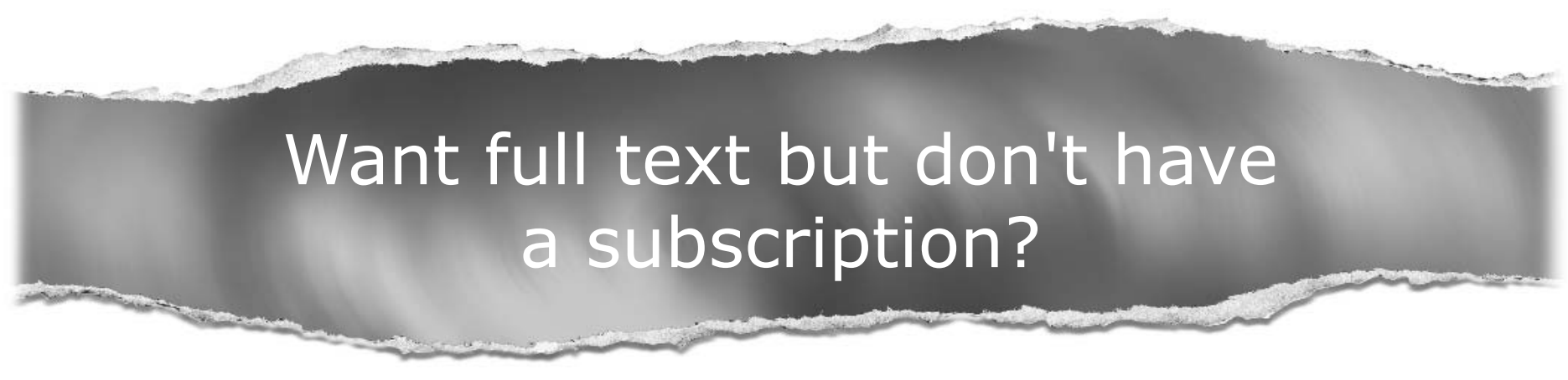

\section{Pay per view}

For just $\$ 8$ you can purchase the full text of individual articles using our secure online ordering service. You will have access to the full text of the relevant article for 48 hours during which time you may download and print the pdf file for personal use.

www.postgradmedj.com 